J. Dairy Sci. 92:548-562

doi:10.3168/jds.2008-1458

(c) American Dairy Science Association, 2009.

\title{
Exercise training of late-pregnant and nonpregnant dairy cows affects physical fitness and acid-base homeostasis
}

\author{
J. A. Davidson ${ }^{1}$ and D. K. Beede ${ }^{2}$ \\ Department of Animal Science, Michigan State University, East Lansing 48824
}

\begin{abstract}
The objective was to determine if exercise training improves physical fitness of nonlactating, late-pregnant and nonpregnant multiparous Holstein cows and alters acid-base homeostasis during an exercise test on a treadmill. Twenty-six pairs (each pair having 1 late-pregnant and 1 nonpregnant) of cows were assigned to treatments of exercise training or no exercise. Exercise training was walking ( 1.25 to $1.5 \mathrm{~h}$ at $3.25 \mathrm{~km} / \mathrm{h}$ ) every other day in an outdoor mechanical walker for $70 \mathrm{~d}$. Cows completed treadmill exercise tests on d 0,30, and 60 of the experiment or about d 70,40, and 10 before expected parturition of the pregnant cow of each pair. On d 0 , physical fitness was similar among all cows based on durations of treadmill tests, heart rates, and acid-base measurements at given workloads $(21.1 \pm 0.6 \mathrm{~min} ; 144$ \pm 2.2 beats per min; plasma lactate $3.1 \pm 1.9 \mathrm{mmol} / \mathrm{L}$; and venous blood $\mathrm{pH} 7.44 \pm 0.0035$, respectively). After $60 \mathrm{~d}$ of training, exercised cows walked longer during treadmill exercise tests compared with nonexercised cows (23.7 vs. $18.3 \pm 0.85 \mathrm{~min}$, respectively), indicating greater physical fitness (pooled across pregnancy status). Heart rates and plasma lactate concentrations at given workloads were less (144 vs. $156 \pm 2.7$ beats per min; and 1.4 vs. $3.2 \pm 0.24 \mathrm{mmol} / \mathrm{L}$ for exercised compared with nonexercised cows, respectively). Additionally, exercised cows more effectively maintained acid-base homeostasis during treadmill tests compared with nonexercised cows. Metabolic, endocrine, and nutritional demands associated with late pregnancy did not affect responses differently to exercise training for late-pregnant compared with nonpregnant cows. Overall, exercise training of late-pregnant and nonpregnant cows for $60 \mathrm{~d}$ improved physical fitness.
\end{abstract}

Key words: exercise, physical fitness, pregnancy, dairy cow

\footnotetext{
Received June 15, 2008.

Accepted October 6, 2008.

${ }^{1}$ Current address: LongView Animal Nutrition Center, Land O'Lakes Purina Feed, LLC, 100 Danforth Drive, Gray Summit, MO

${ }^{2}$ Corresponding author: beede@msu.edu
} 63039.

\section{INTRODUCTION}

Current management systems that limit exercise of dairy cows may reduce their physical fitness during the periparturient period. It is not understood if poor physical fitness may have negative impacts on periparturient health and performance. Fitness is characterized as the maintenance of homeostasis of physiological processes during an exercise challenge (Lamb, 1984). To improve physical fitness, repeated exercise training may cause adaptations of physiological processes to meet increased demands of exercise. This in turn may benefit dairy cows during the periparturient period. For example, improved circulation or changes in blood volume may increase nutrient flows to key organs during the periparturient period. An increase in muscle oxidative capacity or substrate utilization may improve overall energy status of cows. Animal responses may be improved to stress associated with parturition or changes in the environment (e.g., regrouping or facilities that do not provide for optimal cow comfort). Additionally, reduced muscle fatigue after parturition may alter behavior and increase postpartum feed intake. No published work was found examining these possibilities.

In a previous experiment (Davidson and Beede, 2003), exercise training of nonlactating, nonpregnant dairy cows increased physical fitness. Heart rates and blood plasma lactate concentrations of exercised compared with nonexercised cows were lower at given workloads during a treadmill test. Nevertheless, pregnancy in addition to exercise training may affect measurements of physical fitness and acid-base status differently. Heart rates of pregnant women who completed chronic exercise training were less at given workloads compared with sedentary pregnant women, indicating that chronic exercise improved physical fitness (Morton et al., 1985). Metabolic acidosis is the result of addition of strong acid or loss of base (bicarbonate) in the extracellular fluids. During exercise, increasing plasma lactate increases the acid load (metabolic acidosis) of the extracellular fluid. Without compensatory mechanisms of respiration, renal excretion, and extracellular and intracellular buffering, an acid-base disturbance (reduced blood $\mathrm{pH}$ ) will 
result. Chronic exercise training of pregnant dairy cows may reduce metabolic acidosis (reduction in lactate concentrations) during an exercise challenge.

Objectives were to determine 1) if exercise training improves physical fitness of pregnant cows; 2) if pregnancy status and exercise training alter acid-base status during treadmill exercise tests; and 3) if pregnancy status alters physiological responses to exercise. The hypotheses were that exercise training improves physical fitness of both pregnant and nonpregnant, nonlactating cows, causes physiological adaptations to maintain acid-base homeostasis, and that pregnancy status independent of exercise training affects measurements of physical fitness and acid-base homeostasis.

\section{MATERIALS AND METHODS}

Animal care and experimental procedures were approved and conducted under standards of the Michigan State University All-University Committee on Animal Use and Care, application number 05/98-081-00. Guidelines were compliant with National Institutes of Health and the Guide for the Care and Use of Laboratory Animals.

\section{Cows and Treatments}

Twenty-six pairs of nonlactating multiparous Holstein cows (1 late-pregnant and 1 nonpregnant in each pair) were assigned by parity and dry-off date and allocated randomly to experimental treatments. Treatments in a $2 \times 2$ factorial arrangement were exercise training $(\mathbf{E})$ or no exercise (NE), and pregnant $(\mathbf{P})$ or nonpregnant (NP).

Cows had ceased lactation for at least 1 wk before the beginning of the experiment. All cows were trained to use the mechanical walker and treadmill (described subsequently) with 2 to 3 short-duration (5 min) practice sessions 1 to $2 \mathrm{wk}$ before being enrolled in the experiment. The start of experiment for a pair was approximately $70 \mathrm{~d}$ before the expected calving date (ECD) of the pregnant cow. Exercise training was completed every other day until parturition of the pregnant cow.

Experimental Treatments. Exercise training was accomplished outdoors in a mechanical walker with a circular lane that was $90 \mathrm{~cm}$ wide and $33.8 \mathrm{~m}$ long approximately $36.5 \mathrm{~m}$ from the alley in the tie-stall barn where cows were housed (Davidson and Beede, 2003). Cows assigned to NE remained in tie-stalls blocked from feed and water during the time (about $1.5 \mathrm{~h}$ ) cows assigned to E were exercised. From d 2 through 28 of the experiment (about 68 to $42 \mathrm{~d}$ before ECD), E cows walked for $1.25 \mathrm{~h}$ at $3.25 \mathrm{~km} / \mathrm{h}$, and from d 32 to partu- rition for $1.5 \mathrm{~h}$ at $3.25 \mathrm{~km} / \mathrm{h}$. On days of their treadmill tests $(\mathrm{d} 0,30$, and 60 ), cows were not exercised in the mechanical walker.

Diets. All cows were fed a TMR ad libitum, once daily. From d 0 to 34 of experiment, the diet consisted of $47 \%$ alfalfa haylage, $33 \%$ corn silage, $10 \%$ spelt hulls, $9 \%$ soybean meal, plus mineral and vitamins (1.44 Mcal of $\mathrm{NE}_{\mathrm{L}} / \mathrm{kg}, 15.9 \% \mathrm{CP}, 31.5 \% \mathrm{ADF}$, and $45.8 \% \mathrm{NDF}$, dry basis, with a DCAD $[\mathrm{Na}+\mathrm{K}-\mathrm{Cl}-\mathrm{S} \mathrm{mEq} / 100$ $\mathrm{g}$ of dietary DM) of +20.2 . From d 35 to parturition, the diet was $24 \%$ alfalfa haylage, $32 \%$ corn silage, $18 \%$ ground corn, $14 \%$ soybean meal, plus mineral and vitamins (1.65 Mcal of $\mathrm{NE}_{\mathrm{L}} / \mathrm{kg}, 17.7 \% \mathrm{CP}, 22.4 \% \mathrm{ADF}$, $33.3 \% \mathrm{NDF}$, and $-15.7 \mathrm{mEq} / 100 \mathrm{~g}$ of DCAD), dry basis.

\section{Treadmill Exercise Tests}

To assess physical fitness, all cows completed treadmill exercise tests on $\mathrm{d} 0,30$, and 60 of the experiment (about d 70, 40, and 10 before ECD). Exercise tests consisted of increased workloads as cows walked on the treadmill (Classic Treadmill Conditioner, W. H. D. Lindsey, Kenilworth, Australia) located in the barn at the end of the tie-stalls. During tests, heart rates were recorded every $5 \mathrm{~s}$ with a wireless electrocardiogram monitor (Polar Advantage, Polar Electro, Port Washington, NY) as described previously (Davidson and Beede, 2003). Resting heart rates were recorded while cows stood in tie-stalls before being moved to the treadmill and during the minute before beginning of treadmill test (min 0) while standing on the treadmill platform. From min 0 to 3 of the treadmill test, cows walked at $4 \mathrm{~km} / \mathrm{h}$ followed by an increase at min 3 to $5 \mathrm{~km} / \mathrm{h}$ for the remainder of the test. From min 0 to 6 , slope of the walking surface of the treadmill was $0 \%$. Beginning at min 6 , the slope was increased by $0.8 \%$ every $3 \mathrm{~min}$. The test continued until the cow refused to continue walking or until heart rate was at least 180 beats per minute (bpm). In the latter case, tests ended at the end of that 3-min cycle of work after $180 \mathrm{bpm}$ was reached. The time to end of test and the greatest heart rate at the end of test were recorded. At the end of the test, the walking surface was stopped and lowered to a $0 \%$ slope. Cows remained standing on the treadmill platform for 18 min after the exercise portion of the test to measure the return of heart rate to pretest values. Then they moved to their individual tie-stalls.

Blood Sampling. An indwelling catheter was inserted into a jugular vein $1 \mathrm{~d}$ before treadmill tests. Blood was sampled from the catheter into $10-\mathrm{mL}$ syringes containing Na-heparin (20 IU/mL of blood) at min 0 of the treadmill test and before each increase in workload during the test (every $3 \mathrm{~min}$ ). Blood sampling 
continued postexercise every $3 \mathrm{~min}$ for $18 \mathrm{~min}$ (standing on treadmill platform) and every $15 \mathrm{~min}$ from min 33 through 78 (in tie-stalls). Additional sampling was completed in the tie-stalls to verify that circulating metabolites returned to pretest concentrations. Blood $(3 \mathrm{~mL})$ was transferred from the syringe containing Naheparin to a tube with sodium fluoride $(2.5 \mathrm{mg} / \mathrm{mL}$ of blood) for centrifugation $(2,000 \times g)$ within $15 \mathrm{~min}$ of collection. Plasma was harvested and stored at $-20^{\circ} \mathrm{C}$ until analysis for L-lactate. L-Lactate concentrations were determined using the Sport Lactate Analyzer 1500 (YSI, Yellow Springs, OH). Intra- and interassay coefficients of variation were 1.6 and $4.3 \%$, respectively. Remaining blood in capped syringes was immediately placed on ice. Analyses of samples for $\mathrm{pH}$, partial pressure of carbon dioxide $\left(\mathbf{p} \mathbf{C O}_{2}\right)$, hematocrit $(\mathbf{H C T})$, and concentrations of $\mathrm{K}^{+}$, ionized calcium $\left(\mathbf{i C a}^{2+}\right)$, and $\mathrm{Cl}^{-}$began within 15 min after the first sample was collected and proceeded sequentially using a blood gas analyzer (Stat 5 Profiler, Nova Biochemical, Princeton, NJ). From these measurements, concentrations of $\mathrm{HCO}_{3}$, total carbon dioxide, and hemoglobin (HGB) were calculated.

\section{Statistical Analysis}

Data were analyzed by method of least squares ANOVA using mixed model procedures (SAS Institute, 1999). The appropriate covariance structure for the repeated measures (day of the experiment and minute of treadmill test) was determined using the goodness-of-fit criteria of Akaike's information criterion and Schwarz's Bayesian criterion. Plasma L-lactate concentrations had unequal variances across minutes of treadmill test and were transformed using the natural logarithm before analyses. Results are presented as least squares means with SEM. Statistical significance was declared at $P<$ 0.05 ; tendencies were discussed if $0.05<P<0.10$.

Heart rates while cows were in the tie-stalls, at min 0 of treadmill tests, and at the end of treadmill tests were analyzed using the following mixed model: random effect of cow nested within exercise treatment $(\mathbf{T})$ and pregnancy status (PS), repeated measures effect of day of experiment, and fixed effects of T, PS, and pair, and all 2- and 3-way interactions of T, PS, and day of experiment. In the event heart rate of an individual cow was never greater than 150 beats/min during a treadmill test her data were excluded from analyses [7.8\% of total tests (12 of 152)]. Covariance structure of repeated measures effect of day of experiment was first-order auto-regressive. Means for time to end of treadmill test were compared with the orthogonal contrasts: $\mathrm{T}$ effect for d 0 vs. 30 and 60 ; $\mathrm{T}$ effect for $\mathrm{d} 30$ vs. 60; PS effect for d 0 vs. 30 and 60; PS effect for d 30 vs. 60; interaction of $\mathrm{T} \times \mathrm{PS}$ effect for $\mathrm{d} 0$ vs. 30 and 60 ; and interaction of $\mathrm{T} \times \mathrm{PS}$ effect for d 30 vs. 60 .

Patterns of response in heart rates during treadmill exercise tests and frequency of observations by treatment group for heart rate data for each minute of tests pooled across days of experiment are in Figure 1, panels A and B, respectively. Frequency of observations differed among treatment groups due to differences in time to end of the exercise portion of tests (panel B, Figure 1). Because of the reduced frequency of observations beyond $18 \mathrm{~min}$ of tests, only data from min 0 to 18 were used in statistical analyses, so that all treatments and tests were represented with a similar number of observations. Additionally, treadmill tests in which heart rate was never greater than $150 \mathrm{bpm}$ or time to end of the test was $<16$ min were excluded from analyses for dependent variables (heart rates, blood, and plasma variables); 32 of 152 tests were excluded. Of these 32 excluded tests pooled across day of the experiment, the distribution among treatment groups was 4, 16, 4, and 8 for NP, NE; P, NE; NP, E; and P, $\mathrm{E}$, respectively. Four cows (2 in $\mathrm{P}$ and 2 in NP) did not complete the d-60 treadmill tests because parturition occurred earlier than expected for the pregnant cow of each pair.

Heart rate data for every $5 \mathrm{~s}$ were used to calculate the average for each minute during the exercise portion of treadmill tests. During the postexercise portion $(0$ to $12 \mathrm{~min}$ ), 5-s heart rate data were averaged for every $15 \mathrm{~s}$ because of the rapid decline of heart rates. To account for missing heart rate measurements during a given 1-min or 15-s interval, the average heart rate was weighted by the number of observed heart rate measurements within a time interval in the mixed model analyses. Due to the huge amount of data and long computation time to solve the model, the postexercise heart rate data were analyzed as 4 separate data sets: 0 to $3 \mathrm{~min}$; 3 to $6 \mathrm{~min}$; 6 to $9 \mathrm{~min}$; and 9 to $12 \mathrm{~min}$.

The model for the dependent variable heart rate during the treadmill test included the random effect of cow nested within T and PS; the fixed effects of T, PS, and pair; and repeated measures of day of experiment and minute of test. All 2-, 3-, and 4-way interactions of T, PS, day of experiment, and minute of test were included in the model. The covariance structures of these data were unstructured for day of experiment and first-order auto-regressive for minute of test.

Dependent variables of whole blood and plasma concentrations measured during the treadmill test were analyzed separately as 3 data sets: 1 ) exercise portion of test during min 0 to $18 ; 2$ ) postexercise during min 0 to 18 while standing on the treadmill; and 3) postexercise during min 33 to 78 after being returned to tie-stalls. Models included the random effect of cow nested within 

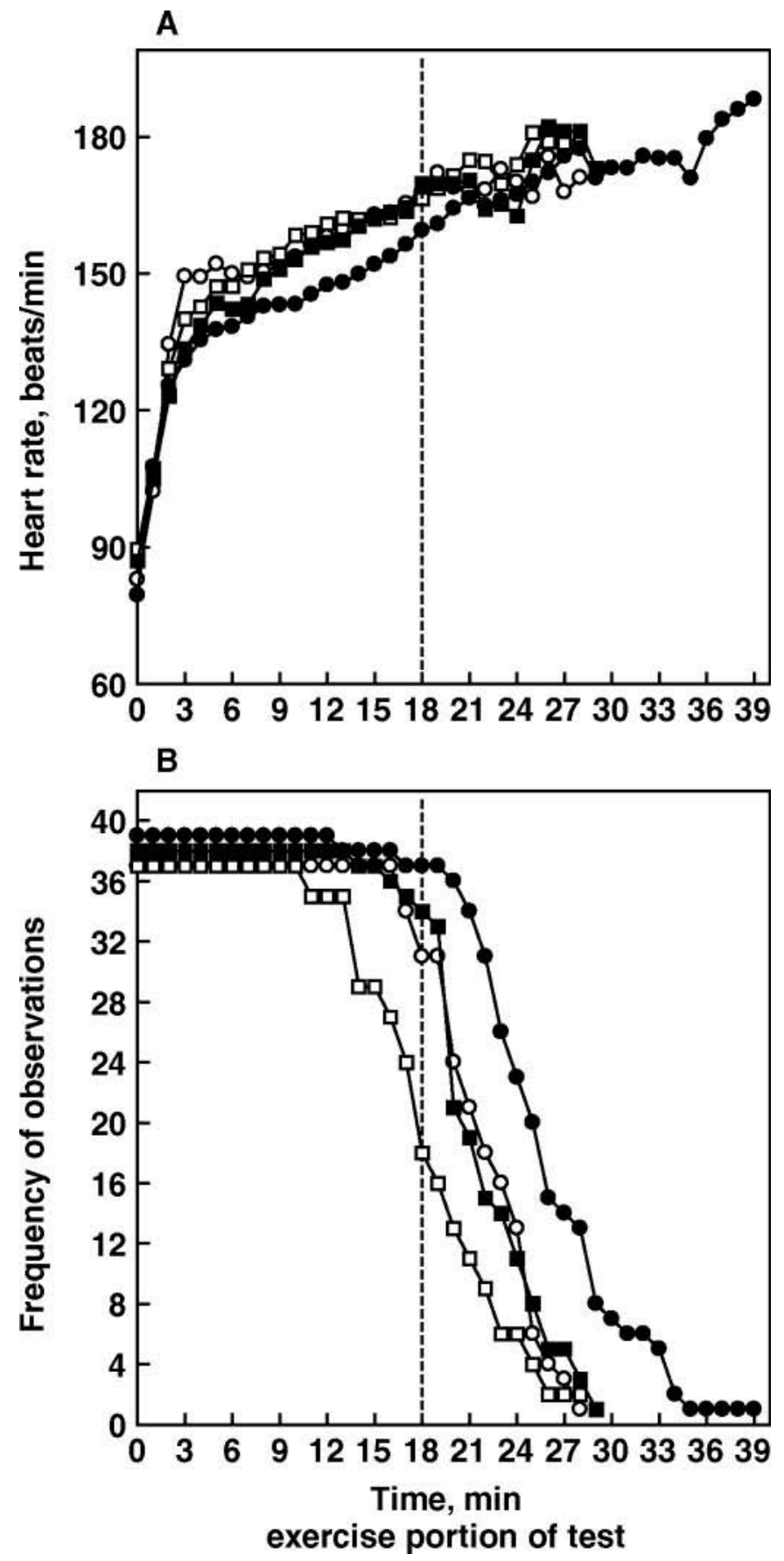

Figure 1. Patterns of mean heart rates (panel A) and frequency of experimental observations (panel B) during treadmill tests pooled across $\mathrm{d} 0,30$, and 60 of the experiment. Treatments were nonpregnant, nonexercise $(\bigcirc)$; pregnant, nonexercise $(\square)$; nonpregnant, exercise (-); and pregnant, exercise (ם). Time to end of tests varied among treatment groups. The vertical dotted line represents min 18 of treadmill tests. Heart rate data during minute of test greater than 18 min were excluded from statistical analyses because of reduced frequency of observations.
$\mathrm{T}$ and PS and the fixed effects of T, PS, and pair, and repeated measures of day of experiment and minute of test. All 2-, 3-, and 4-way interactions of T, PS, day of experiment, and minute of test were included in the model. The covariance structures of the data were unstructured for day of experiment and first-order auto $=$ regressive for minute of test.

\section{RESULTS AND DISCUSSION}

\section{Effects of Exercise Training and Pregnancy on Physical Fitness}

Fitness of cows was evaluated in response to exercise training during the last 2 mo of gestation of the pregnant cow of each pair. In this experiment, time to end of a treadmill test was a primary indicator of change in physical fitness (Davidson and Beede, 2003).

Pooled across pregnancy status, time to end of treadmill tests was $22 \%$ greater for cows after $60 \mathrm{~d}$ of exercise training compared with cows that had not undergone exercise training (contrast of $\mathrm{T}$ effect at $\mathrm{d} 0$ vs. 30 and 60 , interaction of $\mathrm{T} \times$ day of experiment, $P<$ 0.01 , panel A, Figure 2). Cows that exercised regardless of pregnancy status had an $11 \%$ increase in length of time of treadmill tests compared with before training, similar to Davidson and Beede (2003). By comparison, nonpregnant ewes exercised at greater workloads than the cows in our studies had a $40 \%$ greater length of time of the exercise test compared with length of time before training (Mundie et al., 1991).

On d 60, time to end of treadmill test was about $25 \%$ less for pregnant than nonpregnant cows (pooled across exercise treatments, contrast of PS effect at d 0 vs. 30 and 60 , interaction of PS $\times$ day of experiment, $P<0.01$, panel B, Figure 2). Similar results from other studies with exercise training of pregnant ruminants were not found. The 3-way interaction of $\mathrm{T} \times \mathrm{PS} \times$ day of experiment was not significant $(P$ $=0.12)$. Nevertheless, results suggested that exercise training and pregnancy status may have had differing influence on time to end of the treadmill tests over the course of the training period (day of experiment; panel C, Figure 2).

As cows approached parturition, the additional mass associated with the conceptus, endocrine or metabolic energy demands, or both may have contributed to the reduction in performance during treadmill tests. Yet, by $\mathrm{d} 60$, pregnant and nonpregnant cows that exercised ( $\mathrm{P}$, E and NP, E) had treadmill tests $22 \%$ longer compared with nonexercised cows (P, NE and NP, NE). Thus, cows that exercised for $60 \mathrm{~d}$ were more physically fit compared with cows that did not exercise based on the extended length of time of treadmill tests. 


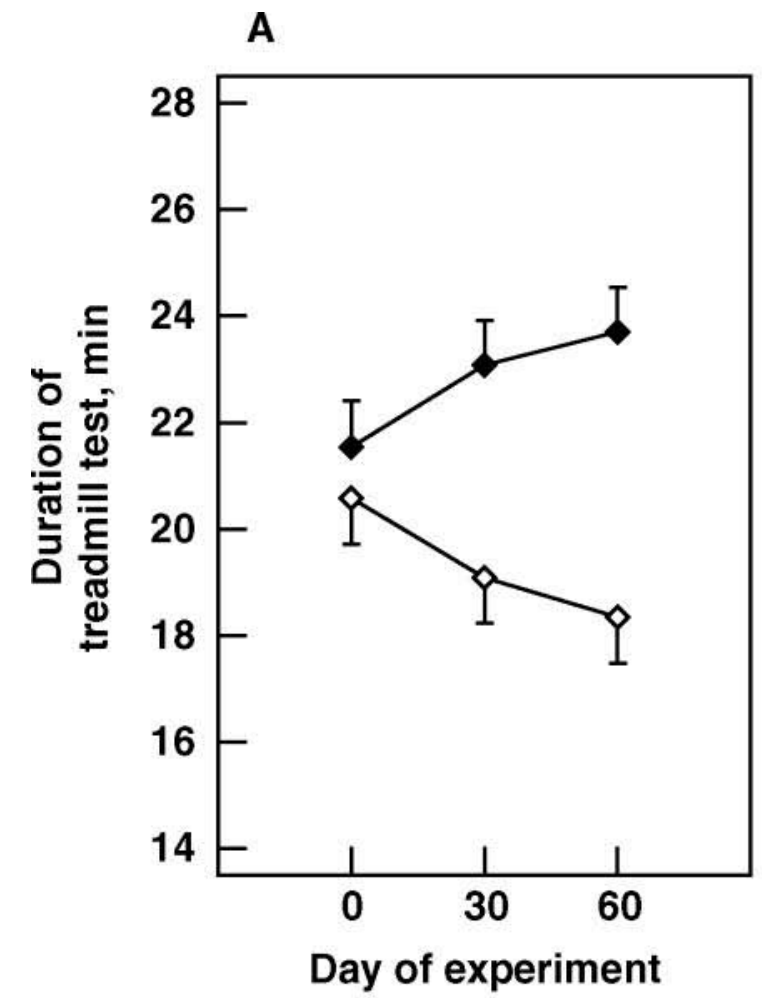

B
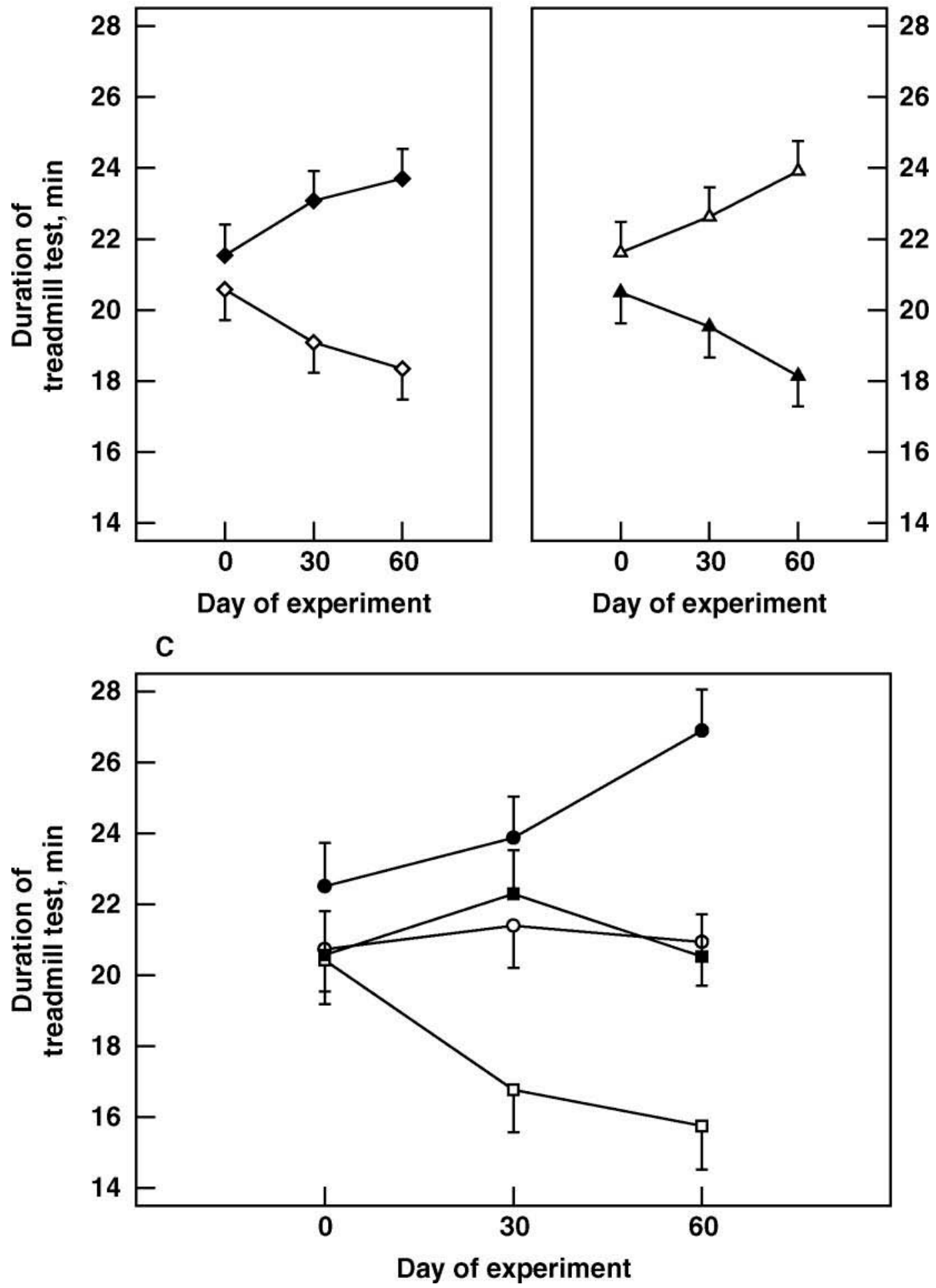

Figure 2. Time to end of treadmill test on d 0,30, and 60 of the experiment. Panel A: pooled across pregnancy status, treatments were exercise $(\checkmark)$ and nonexercise $(\diamond)$. Interaction of treatment $\times$ day of experiment affected time to end of treadmill test $(P<0.05)$. Panel B: pooled across exercise treatments, treatments were pregnant $(\boldsymbol{\Delta})$ and nonpregnant $(\Delta)$. Interaction of pregnancy status by day of experiment affected time to end of treadmill tests $(P<0.05)$. Panel C: Treatments were nonpregnant, nonexercise $(\bigcirc)$; nonpregnant, exercise $(\bullet)$; pregnant, nonexercise $(\square)$; and pregnant, exercise $(\square)$. Three-way interaction of treatment $\times$ pregnancy status $\times$ day of experiment approached significance $(P=0.12)$. 
Table 1. Heart rates (beats per minute) before treadmill test in tie-stalls, at min 0 on treadmill, and at end of the exercise portion of the test ${ }^{1}$

\begin{tabular}{|c|c|c|c|c|c|c|c|}
\hline \multirow[b]{2}{*}{ Independent variable } & \multicolumn{3}{|c|}{ Day of experiment } & \multirow[b]{2}{*}{ SEM } & & \multirow[b]{2}{*}{$P$-value ${ }^{2}$} & \\
\hline & 0 & 30 & 60 & & & & \\
\hline Tie-stalls & & & & & PS & $\mathrm{D}$ & $\mathrm{PS} \times \mathrm{D}$ \\
\hline $\begin{array}{l}\mathrm{NP}^{3} \\
\mathrm{P}^{3}\end{array}$ & $\begin{array}{l}75.4 \\
75.8\end{array}$ & $\begin{array}{l}77.4 \\
79.7\end{array}$ & $\begin{array}{l}81.8 \\
89.4\end{array}$ & $\begin{array}{l}1.40 \\
1.45\end{array}$ & NS & $<0.001$ & 0.036 \\
\hline At min 0 of test & & & & & PS & $\mathrm{D}$ & $\mathrm{PS} \times \mathrm{D}$ \\
\hline $\begin{array}{l}\mathrm{NP}^{3} \\
\mathrm{P}^{3}\end{array}$ & $\begin{array}{l}80.9 \\
82.1\end{array}$ & $\begin{array}{l}79.1 \\
87.2\end{array}$ & $\begin{array}{l}84.6 \\
95.9\end{array}$ & $\begin{array}{l}1.85 \\
1.89\end{array}$ & $<0.001$ & $<0.001$ & 0.022 \\
\hline & & & & & $\mathrm{T}$ & $\mathrm{D}$ & $\mathrm{T} \times \mathrm{D}$ \\
\hline $\begin{array}{l}\mathrm{NE}^{4} \\
\mathrm{E}^{4}\end{array}$ & $\begin{array}{l}81.4 \\
81.6\end{array}$ & $\begin{array}{l}85.5 \\
80.8\end{array}$ & $\begin{array}{l}93.4 \\
87.2\end{array}$ & $\begin{array}{l}1.89 \\
1.85\end{array}$ & 0.06 & $<0.001$ & NS \\
\hline At end of test & & & & & PS & $\mathrm{D}$ & $\mathrm{PS} \times \mathrm{D}$ \\
\hline Pooled $^{5}$ & 175.5 & 179.9 & 182.9 & 2.43 & NS & 0.099 & NS \\
\hline
\end{tabular}

${ }^{1}$ Values are least squares means.

${ }^{2} \mathrm{~T}=$ exercise treatment; PS = main effect of pregnancy status; $\mathrm{D}=$ main effect of day of experiment; $\mathrm{T} \times \mathrm{D}$ $=$ interaction of exercise treatment $\times$ day of experiment; PS $\times \mathrm{D}=$ interaction of pregnancy status $\times$ day of experiment; and $\mathrm{NS}=P>0.10$.

${ }^{3}$ Least squares means pooled across exercise treatments. $\mathrm{T} \times \mathrm{PS}$ interaction $(P>0.10) . \mathrm{NP}=$ nonpregnant cows; and $\mathrm{P}=$ pregnant cows.

${ }^{4}$ Least squares means pooled across pregnancy status. $\mathrm{T} \times \mathrm{PS}$ interaction $(P>0.10) . \mathrm{NE}=$ nonexercised cows; and $\mathrm{E}=$ exercised cows

${ }^{5}$ Least squares means pooled across exercise treatment and pregnancy status. $\mathrm{T} \times \mathrm{PS}$ interaction $(P>0.10)$.

\section{Effects of Exercise Training and Pregnancy on Heart Rate}

In the current experiment, heart rates were used to quantify the effort of a cow's heart when subjected to varying workloads before and after exercise training. Exercise training did not affect resting heart rates of cows standing in tie-stalls before treadmill tests regardless of pregnancy status (Table 1). Cows that exercised tended to have slightly reduced heart rates at min 0 on the treadmill compared with nonexercised cows (pooled across pregnancy status and day of experiment, $P=$ $0.06)$. In horses and steers, cardiac output increased linearly with increased workloads (Jones et al., 1989). During exercise, cardiac output correlated well with increased heart rates, but not with stroke volume.

As day of gestation advanced, pregnant cows had an increase of resting heart rates compared with nonpregnant cows (interaction of PS $\times$ day of experiment, $P$ $<0.05$, Table 1). In women, pregnancy increased resting heart rates (Clapp, 1985). Similar to the current study with cows, chronic exercise training of pregnant women who had not trained previously did not reduce this increase in resting heart rates (Erkkola, 1976). This increase in resting heart rates during pregnancy may be associated with increases in conceptus mass, vascularization of reproductive organs, blood volume, and metabolic activity.

When workloads increased systematically during the treadmill tests, exercise training, pregnancy status, and day of experiment influenced heart rates (4-way interaction of T $\times$ PS $\times$ day of experiment $\times$ minute of test; $P<0.05$, Figure 3). On d 0 of the experiment, heart rates during tests increased similarly for all treatment groups (Figure 3). This is similar to our previous results in which nonexercised cows had greater increases in heart rates due to treadmill exercise tests compared with cows in exercise training (Davidson and Beede, 2003). Similarly, horses exercised for 5, 10, or $16 \mathrm{wk}$ had lower heart rates during exercise testing compared with unexercised horses (Thomas et al., 1983).

In the current study, experimental treatments did not affect the magnitude of the greatest heart rates recorded at the end of treadmill tests. As in other studies, maximum heart rates of nonruminants or ruminants did not increase after exercise training (Fosha-Dolezal and Fedde, 1988; Aguera et al., 1995; Davidson and Beede, 2003). Nonetheless, in the current study exercise training did affect the amount of time and magnitude of workload for cows to achieve their greatest heart rates, similar to previous results (Davidson and Beede, 2003). 

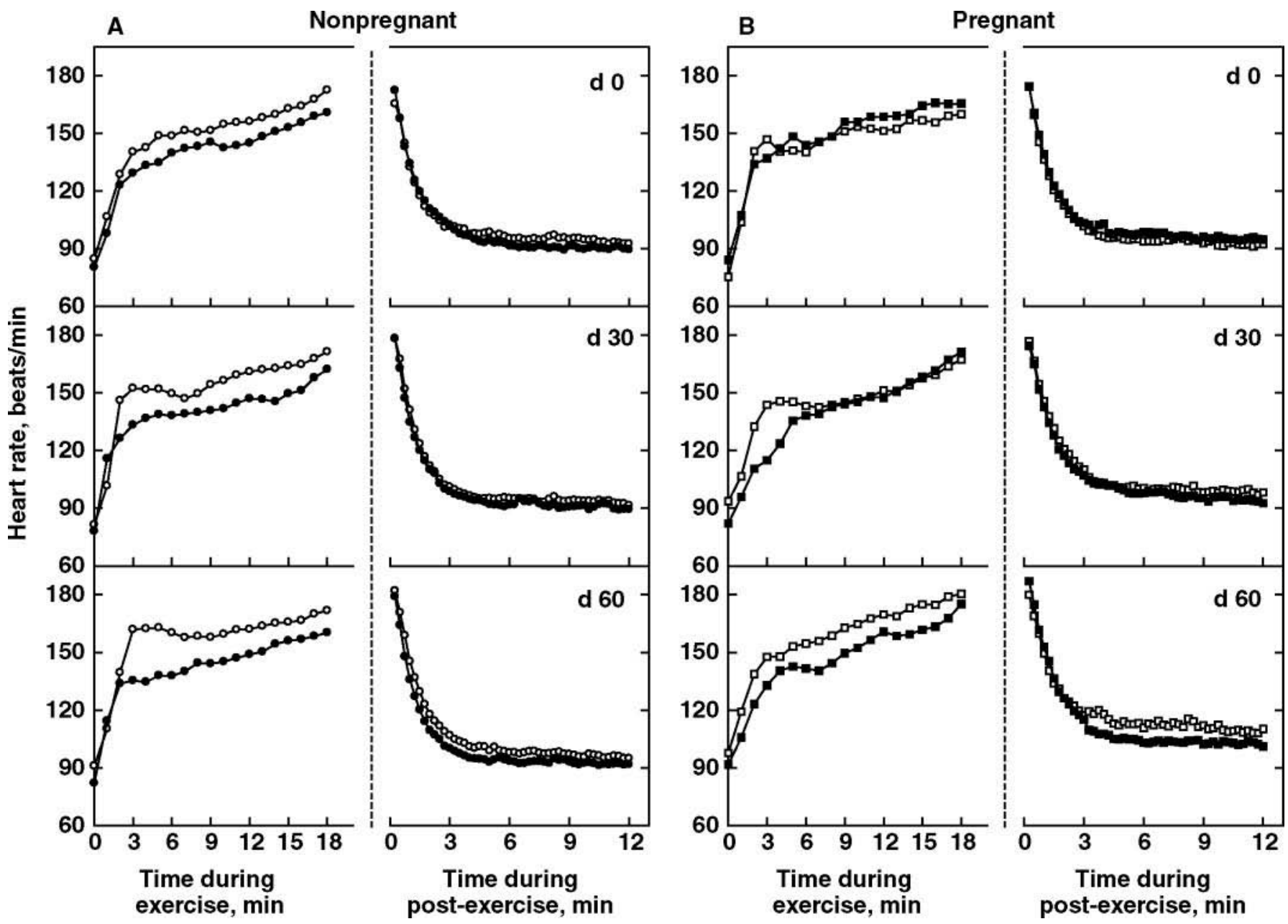

Figure 3. Heart rates during exercise and postexercise portions of treadmill tests on d 0,30 , and 60 of the experiment. Treatments were nonpregnant, nonexercise $(\bigcirc)$; nonpregnant, exercise $(\bullet)$; pregnant, nonexercise $(\square)$; and pregnant, exercise ( $\square)$. Panel A shows results for nonpregnant cows and panel B for pregnant cows. During treadmill tests, heart rates were affected by the interaction of exercise treatment $\times$ pregnancy status $\times$ day of experiment $\times$ minute of test (pooled SEM $=7.31, P<0.05$ ). During 0 to 3 min postexercise, pregnancy $\times$ minute postexercise interaction was significant (pooled SEM $=6.04, P<0.05$ ). During 3 to 6 min postexercise, interaction of pregnancy status $\times$ day of experiment $\times$ minute tended to be significant (pooled SEM $=4.12, P=0.07$ ), and treatment $\times$ day of experiment interaction was significant $(P<0.05)$. During 6 to 9 min postexercise, interaction of pregnancy status $\times$ day of experiment tended to be significant $($ pooled SEM $=3.92$, $P=0.08)$; and treatment $\times$ minute postexercise interaction tended to be significant $(P=0.06)$. During 9 to 12 min postexercise, interaction of exercise treatment $\times$ pregnancy status $\times$ day of experiment was significant (pooled SEM $=3.88, P<0.05$ ).

In the current study, heart rates in all treatments declined rapidly during the first 3 min after the treadmill was stopped (postexercise effect of minute of test, $P<$ 0.001 ) and continued to decline during min 3 to 6 (Figure 3). During min 3 to 6 on d 60 , heart rates were less for $\mathrm{E}$ compared with $\mathrm{NE}$ cows (interaction of $\mathrm{T} \times$ day of experiment, $P=0.032$ ). After min 6 postexercise, differences in heart rates among all treatment groups and tests were small and similar to differences among treatment groups for measured resting values. Similar postexercise heart rate patterns were reported for horses (Ehrlein et al., 1973). Time required for heart rates to return to resting states can be affected by magnitude of workloads and duration of work, environmental temperature and humidity, and working capacity of the horse (Fregin and Thomas, 1983).

As most evident on d 60 of the experiment, postexercise decline in heart rates was not as great for $\mathrm{P}$ cows compared with NP cows (interaction of PS $\times$ day of experiment, $P<0.05$ ). This difference was similar to differences detected between measured resting values of $\mathrm{P}$ and NP cows. Similarly, increase in resting heart rates was not reduced in pregnant women in chronic training (Erkkola, 1976).

In our study, reduction of heart rates during the exercise portion of treadmill tests after $30 \mathrm{~d}$ indicated that exercised cows were more physically fit than nonexercised cows. They completed given workloads with lower 
cardiac frequency. Also, the slightly greater heart rates of pregnant compared with nonpregnant cows could be related to differences in conceptus mass and increased vascularization of tissues associated with pregnancy.

\section{Effects of Exercise Training and Pregnancy on Acid-Base Status}

Results of studies are sparse characterizing acid-base physiology during exercise of pregnant ruminants. Davidson and Beede (2003) showed that acute exercise of NP, nonlactating dairy cows resulted in transient changes in plasma concentrations of L-lactate (acid load of metabolic acidosis) and blood $\mathrm{pH}, \mathrm{pCO}_{2}, \mathrm{HCO}_{3}{ }^{-}$, and total $\mathrm{CO}_{2}$. In the present experiment, acid-base responses to exercise training and pregnancy were within normal physiological ranges during treadmill tests. All cows were able to compensate for increased plasma lactate concentrations (Figure 4). Indicators of blood acid-base status were within normal physiological ranges (Figures 5, 6, 7, and 8) and tightly controlled by compensatory mechanisms.

Plasma L-Lactate. On d 0 of the experiment during the exercise portion of treadmill tests, plasma lactate concentrations increased similarly in all treatment groups from about 1.1 to $4.4 \mathrm{mmol} / \mathrm{L}$ (from about 1.0 to 1.1 at $0 \mathrm{~min}$ to between 3.4 and $5.0 \mathrm{mmol} / \mathrm{L}$ at 18 min of test; Figure 4). Concentrations increased from
A

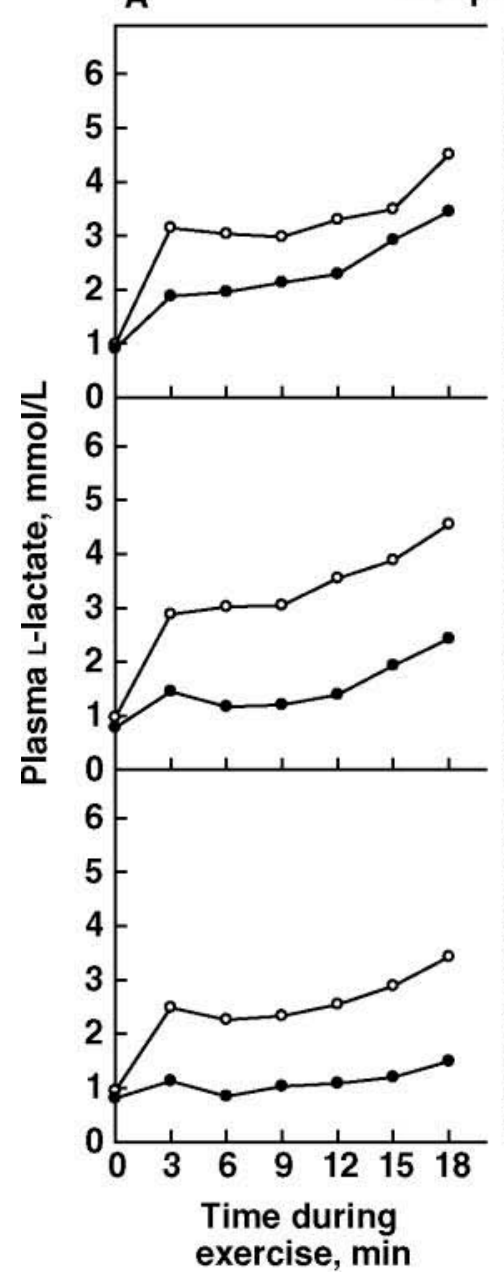

Nonpregnant

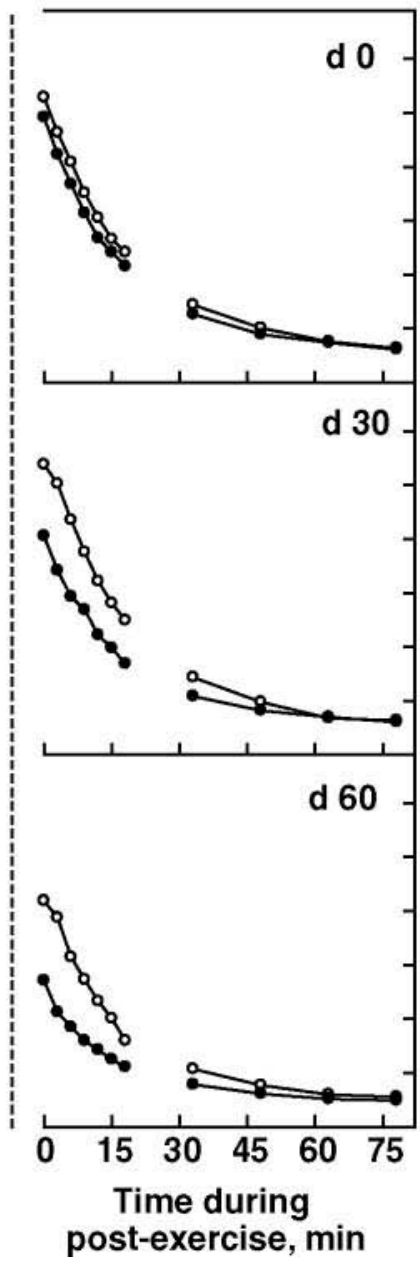

B

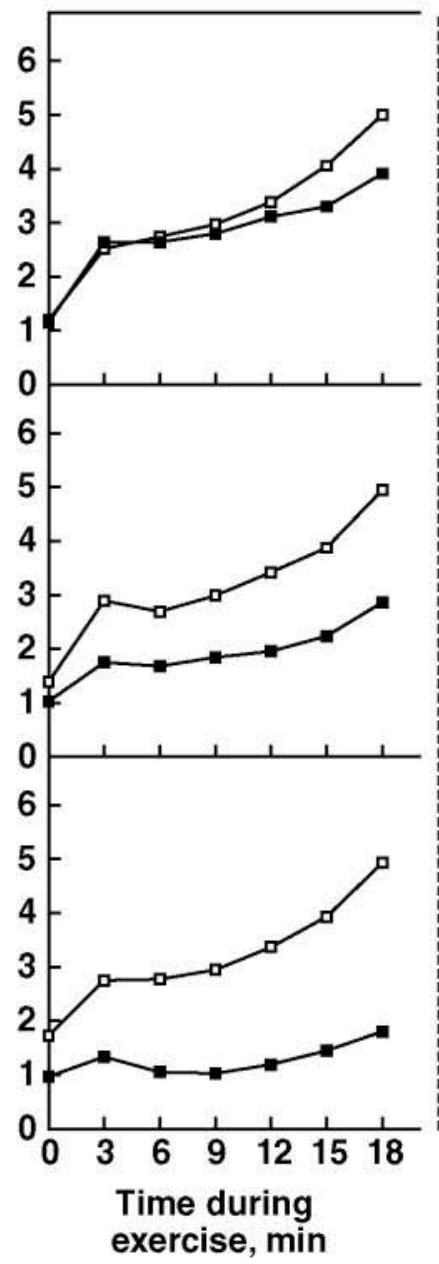

Pregnant

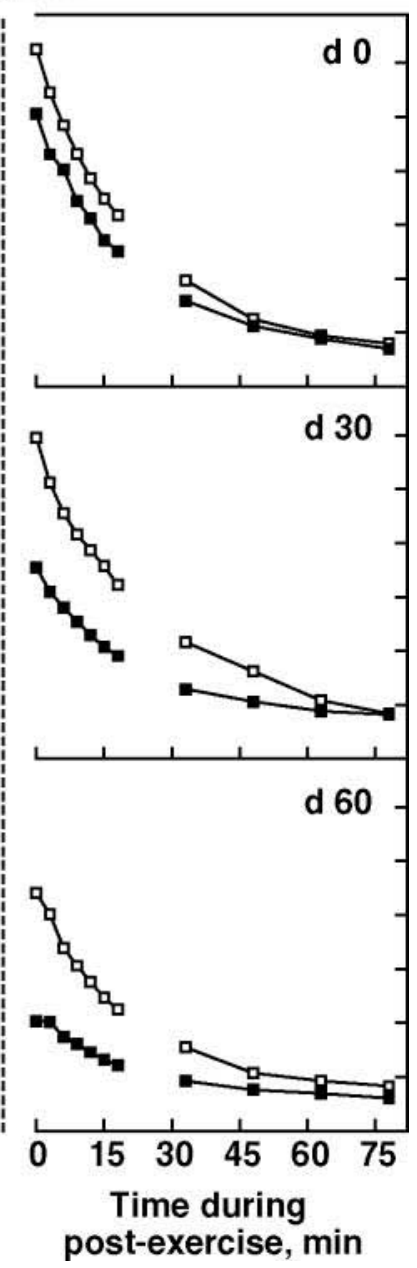

Figure 4. Plasma L-lactate concentrations (back-transformed general least squares means) during the exercise and postexercise portions of treadmill tests on d 0, 30, and 60 of the experiment. Treatments were nonpregnant, nonexercise (O); nonpregnant, exercise (-); pregnant, nonexercise $(\square)$; and pregnant, exercise ( $\mathbf{\square})$. Panel A shows results for nonpregnant cows, and panel B shows results for pregnant cows. During min 0 to 18 of exercise, interaction of exercise treatment $\times$ pregnancy status $\times$ minute of test and the interaction of exercise treatment $\times$ day of experiment affected plasma lactate concentrations $(P<0.02)$. During min 0 to 18 postexercise, plasma lactate was affected by interaction of exercise treatment $\times$ day of experiment and the interaction of pregnancy status $\times$ minute of test $(P<0.05)$. During min 33 to 78 postexercise, interaction of exercise treatment $\times$ minute was significant $(P=0.007)$; also, pregnancy status was significant during this time $(P<0.001)$. 

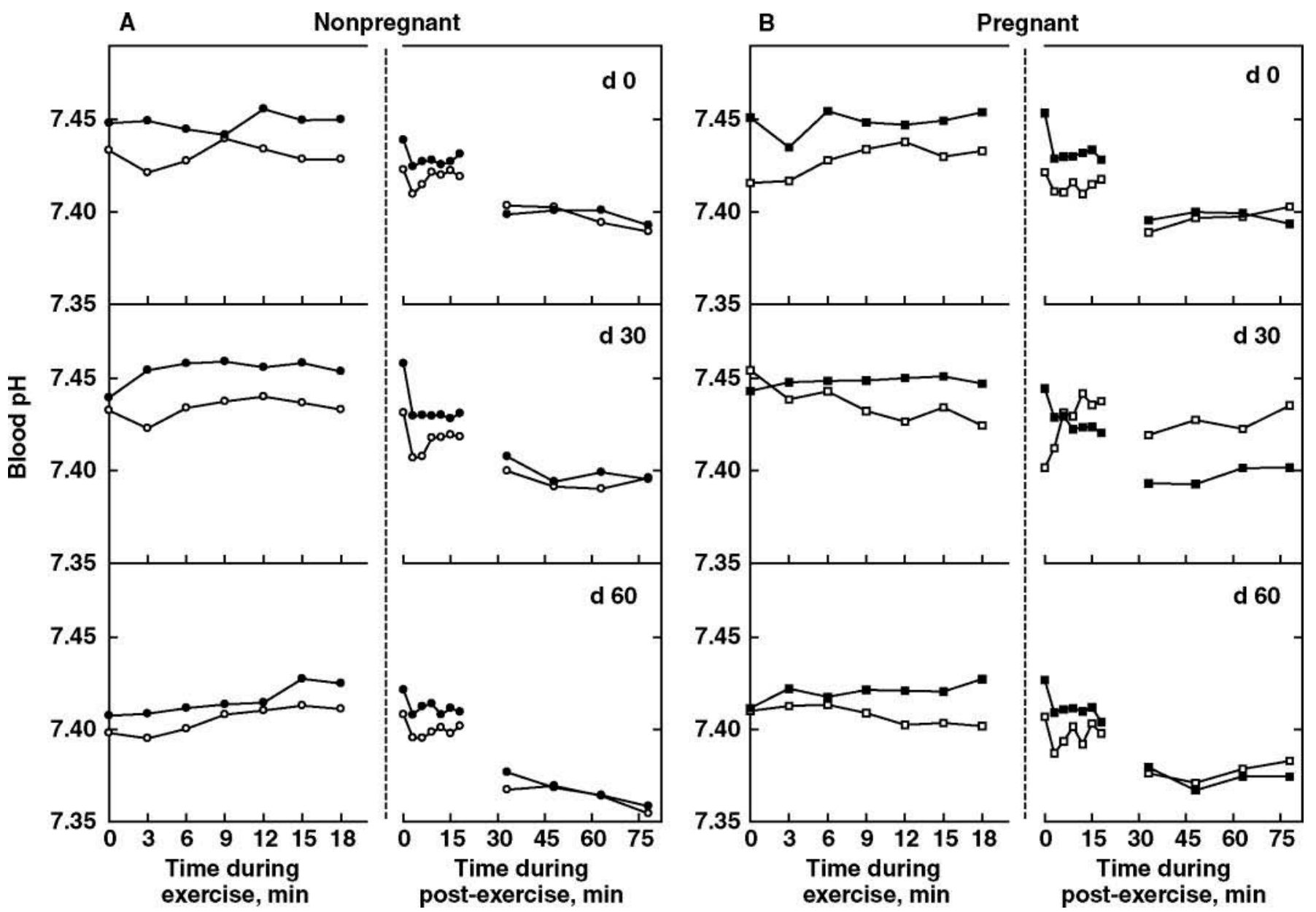

Figure 5. Blood $\mathrm{pH}$ during exercise and postexercise portions of treadmill tests on $\mathrm{d} 0,30$, and 60 of the experiment. Treatments were nonpregnant, nonexercise $(\bigcirc)$; nonpregnant, exercise $(\bullet)$; pregnant, nonexercise $(\square)$; and pregnant, exercise $(\boldsymbol{\square})$. Panel A shows results for nonpregnant cows, and panel B shows results for pregnant cows. During exercise, blood $\mathrm{pH}$ was affected by interaction of exercise treatment $\times$ pregnancy status $\times$ day of experiment $\times$ minute of test (pooled SEM $=0.0116, P=0.053$ ). During 0 to 18 min postexercise, interaction of exercise treatment $\times$ pregnancy status $\times$ day of experiment $\times$ minute of test (pooled SEM $=0.00957, P=0.088$ ) and interaction of pregnancy status $\times$ day of experiment $\times$ minute of test $(P<0.001)$. During 33 to 78 min postexercise, interaction of pregnancy status $\times$ minute of test was significant (pooled $\mathrm{SEM}=0.0116, P=0.030$ ).

1.1 to $8.8 \mathrm{mmol} / \mathrm{L}$ when Hereford calves exercised for 5 $\min$ at $7.9 \mathrm{~km} / \mathrm{h}$, almost twice the exercise speed used in the current study (Kuhlmann et al., 1985; FoshaDolezal and Fedde, 1988).

After $60 \mathrm{~d}$ of exercise training, increases in plasma lactate concentrations during treadmill tests were less for exercised than nonexercised cows (approximately 1.7 vs. $3.3 \mathrm{mmol} / \mathrm{L}$, respectively; interaction of $\mathrm{T} \times$ day of experiment, $P<0.001$, Figure 4 ). These results were similar to responses of exercise-trained horses where plasma lactate was less during an exercise test compared with pretraining values (Rodiek et al., 1987; Aguera et al., 1995). Additionally, lactate concentrations pooled across days were greater for nonexercised (NP, NE and P, NE) compared with exercised cows (NP, E and P, E). Furthermore, pregnant cows that exercised had greater concentrations of plasma lactate than nonpregnant cows that exercised (interaction of $\mathrm{T}$ $\times$ PS $\times$ minute of test; $P=0.017$; Figure 4 ).

During min 0 to 18 postexercise, all cows had similar patterns of decreasing plasma lactate concentrations on d 0 of experiment $(P<0.001$; Figure 4$)$. After 60 $d$ of exercise training, cows that exercised had lesser plasma lactate concentrations during min 0 to $18 \mathrm{~min}$ postexercise compared with cows that did not exercise (interaction of $\mathrm{T} \times$ day of experiment, $P=0.045$; Figure 4). Furthermore, plasma lactate declined more for nonpregnant cows than pregnant cows (interaction of PS $\times$ minute of test, $P<0.001$; Figure 4). During the extended period of time postexercise (min 33 to 78), $\mathrm{P}$ cows had greater plasma lactate concentrations than NP cows $(P<0.001)$. Lactate concentrations of 
all cows returned to preexercise values by about $75 \mathrm{~min}$ after end of treadmill tests. After cessation of activity, concentrations of blood lactate of draft ruminants declined to resting values by $30 \mathrm{~min}$ (Zanzinger and Becker, 1992).

Overall, plasma lactate concentrations among all treatment groups increased during the exercise portion of treadmill tests on d 0,30 , and 60 . Increased plasma lactate concentrations during treadmill tests suggest an increase of anaerobic metabolism and subsequent metabolic acidosis. After $60 \mathrm{~d}$ of exercise training, plasma lactate concentrations during similar workloads and postexercise periods were less for exercised than nonexercised cows. Therefore, cows that were trained experienced less metabolic challenge associated with anaerobic metabolism and metabolic acidosis. This change could be due to a direct improvement in cellular metabolism with less challenge of anaerobiosis in active tissues, the likelihood that there were changes in release and uptake (net flux) of lactate by organs that resulted in decreased blood plasma concentrations, or both.

Blood $\boldsymbol{p H}$. During the exercise portion of treadmill tests, changes of venous blood $\mathrm{pH}$ were very small and within the normal physiological range for dairy cows (Figure 5). Cows were able to compensate for the increased plasma lactate load to prevent a disturbance in blood acid-base balance. Similarly, exercise training did not affect blood acid-base profiles in a previous ex-
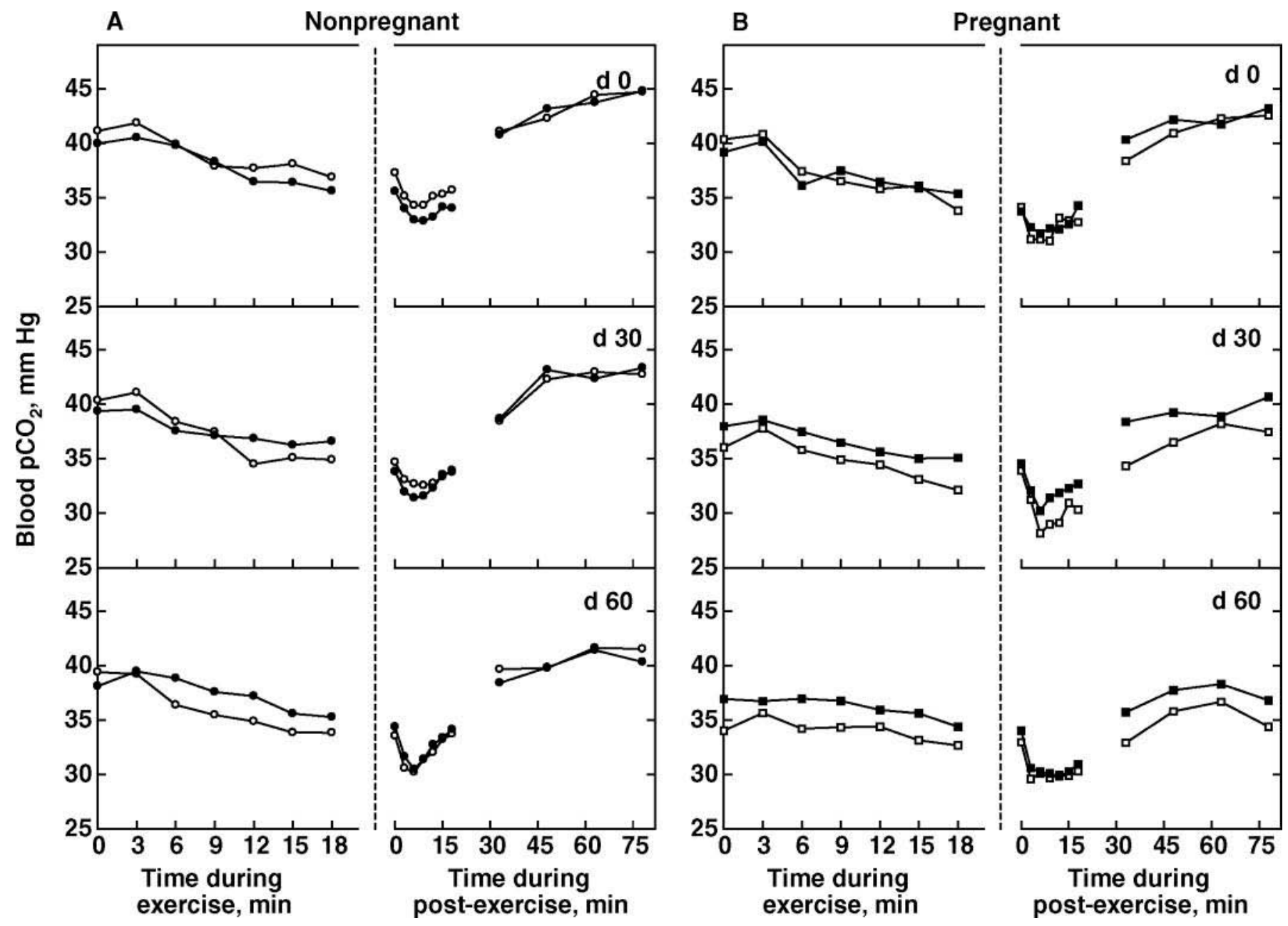

Figure 6. Blood partial pressure of carbon dioxide $\left(\mathrm{pCO}_{2}\right)$ during exercise and postexercise portions of treadmill tests on d 0,30 , and 60 of the experiment. Treatments were nonpregnant, nonexercise $(\bigcirc)$; nonpregnant, exercise (-); pregnant, nonexercise $(\square)$; and pregnant, exercise $(\square)$. Panel A shows results for nonpregnant cows, and panel B shows results for pregnant cows. During exercise, blood $\mathrm{pCO}_{2}$ was affected by minute of test $(P<0.001)$, pregnancy status $(P=0.015)$, and interaction of exercise treatment $\times$ day of experiment $(P=0.046$, pooled SEM $=1.597)$. During 0 to 18 min postexercise, minute of test $(P<0.001)$, pregnancy status $(P=0.003)$, and interaction of pregnancy status $\times$ day of experiment $\times$ minute of test (pooled SEM $=1.204, P=0.030)$ were significant. During 33 to 78 min postexercise, minute of test $(P<$ $0.001)$, pregnancy status $(P<0.001)$, interaction of pregnancy status $\times$ day of experiment $(P=0.084)$, and interaction of exercise treatment $\times$ pregnancy status $(P=0.057)$ tended to be significant (pooled SEM $=1.645)$. 
periment with nonlactating, nonpregnant cows though lactate concentrations were not as large (Davidson and Beede, 2003).

In the current study, venous blood $\mathrm{pH}$ ranged between 7.38 and 7.46 across all groups and times of the exercise and postexercise portions of treadmill tests. There was an interaction of $\mathrm{T} \times$ day of experiment $\times$ minute of test, and an interaction of PS $\times$ day of experiment $\times$ minute of test on blood $\mathrm{pH}$ during the exercise portion of treadmill tests $(P<0.03$; Figure 5$)$. During postexercise min 33 to 78 , no $\mathrm{T}$ effects were detected, but the interaction of PS $\times$ minute of test was detected for blood $\mathrm{pH}(P=0.038)$. Even though our model detected significant effects of exercise and pregnancy on venous blood $\mathrm{pH}$, the relatively small differences across the entire study indicated that all cows were able to compensate adeptly for the increased metabolic acidosis to prevent a large shift of blood $\mathrm{pH}$.

Among all cows, postexercise values of blood $\mathrm{pH}$ were slightly less than preexercise values before treadmill tests. Cows may have slightly overcompensated for metabolic acidosis experienced during the exercise portion of tests. After cessation of exercise, respiratory and renal systems likely influenced acid-base status during postexercise period. Respiration rates were not measured in the current experiment. Yet, respiration rates of calves after $15 \mathrm{~min}$ of exercise at $4.0 \mathrm{~km} / \mathrm{h} \mathrm{re}-$ mained greater for $15 \mathrm{~min}$ postexercise than preexercise values (Piguet et al., 1993). Additionally, respiration rates of dairy cows after $18 \mathrm{~min}$ of exercise at $5.4 \mathrm{~km} / \mathrm{h}$
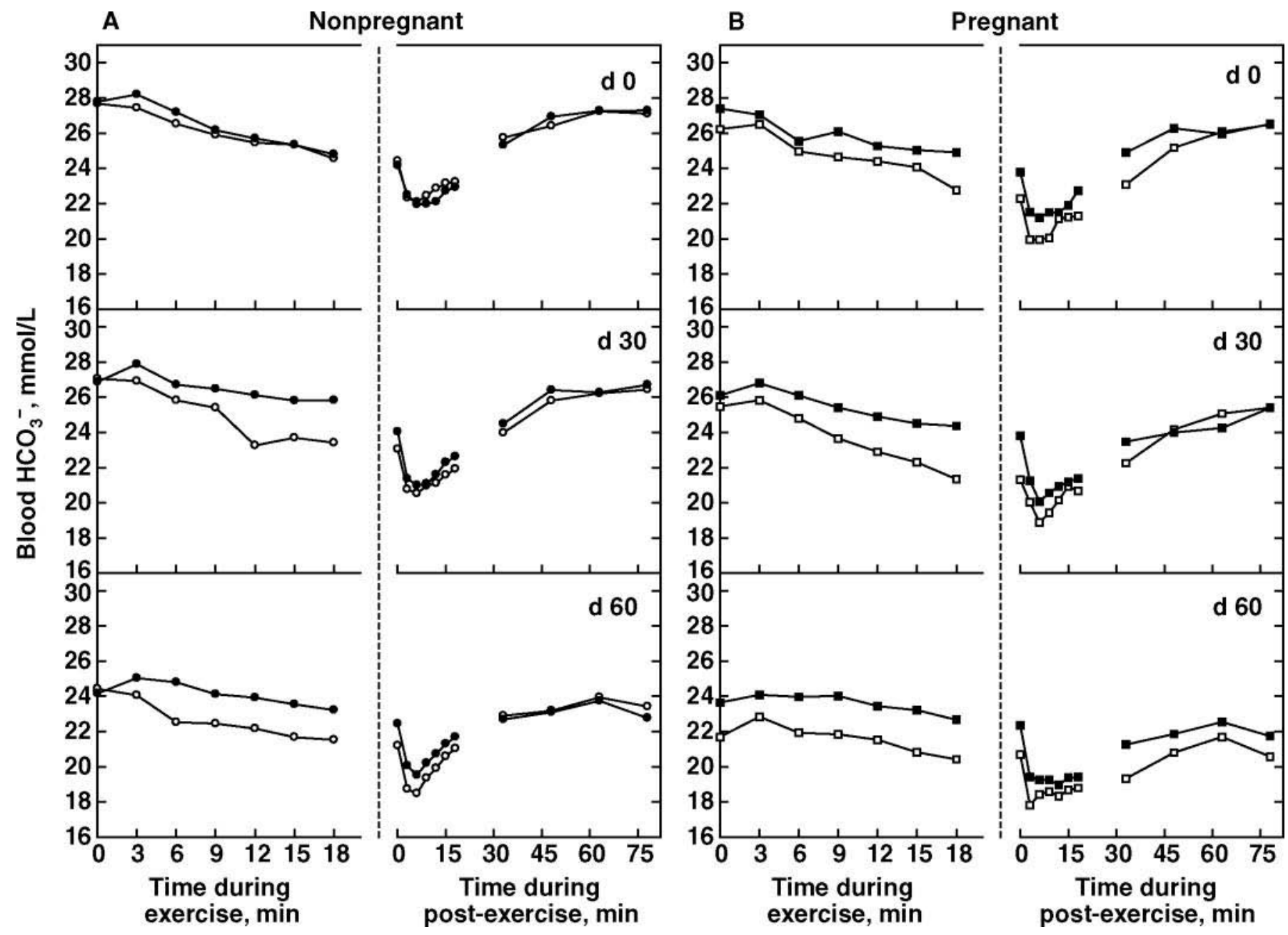

Figure 7. Blood $\mathrm{HCO}_{3}{ }^{-}$concentrations during exercise and postexercise portions of treadmill tests on d 0 , 30, and 60 of the experiment. Treatments were nonpregnant, nonexercise $(\bigcirc)$; nonpregnant, exercise $(\bullet)$; pregnant, nonexercise $(\square)$; and pregnant, exercise $(\mathbf{\square})$. Panel A

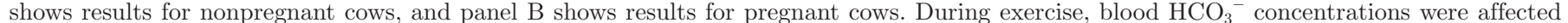
by minute of test $(P<0.001)$, pregnancy status $(P=0.039)$, and exercise treatment $(P=0.007$, pooled SEM $=1.099)$. During 0 to 18 min postexercise, minute of test $(P<0.001)$, pregnancy status $(P=0.013)$, and interaction of pregnancy status $\times$ day of experiment $\times$ minute of test (pooled SEM $=0.843, P=0.037$ ) were significant. During 33 to 78 min postexercise, minute of test and pregnancy status were significant (pooled $\mathrm{SEM}=0.852 ; P<0.001)$. 


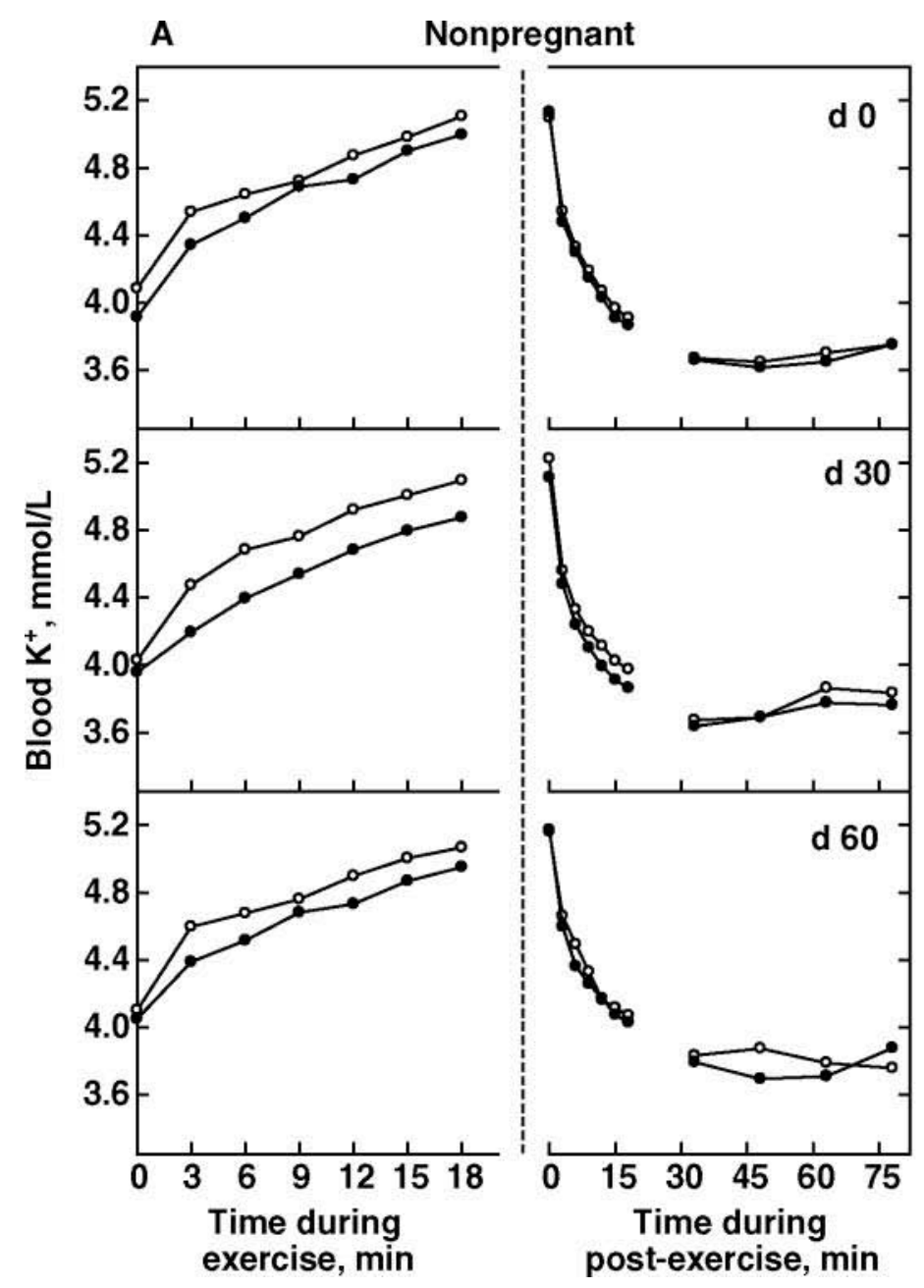

B

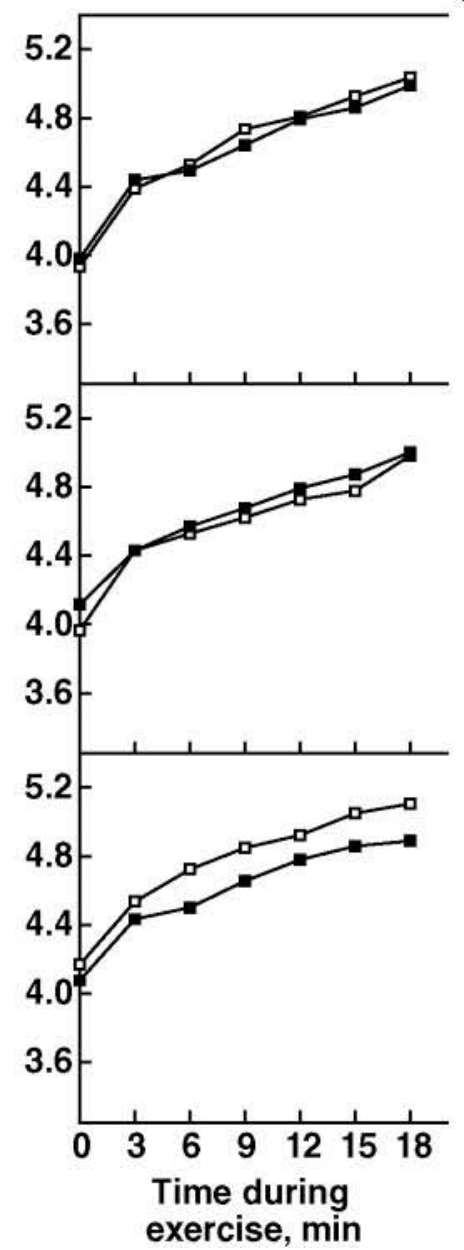

Pregnant

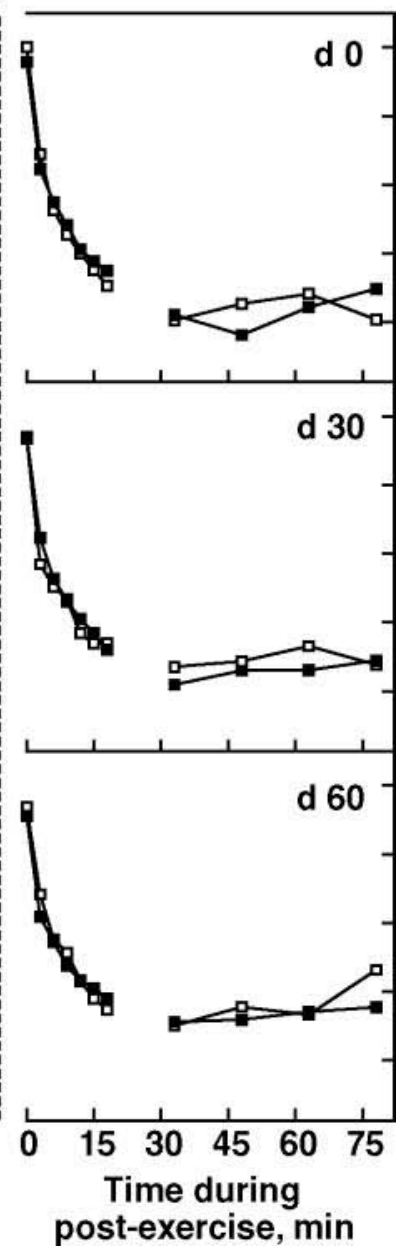

Figure 8. Blood $\mathrm{K}^{+}$concentrations during exercise and postexercise portions of treadmill tests on d 0 , 30, and 60 of the experiment. Treatments were nonpregnant, nonexercise $(\bigcirc)$; nonpregnant, exercise $(\bullet)$; pregnant, nonexercise $(\square)$; and pregnant, exercise $(\boldsymbol{\square})$. Panel A shows results for nonpregnant cows, and panel B shows results for pregnant cows. During exercise, blood $\mathrm{K}^{+}$concentrations were affected by minute of test $(P<0.001)$, and interaction of treatment $\times$ pregnancy status $\times$ day of experiment $(P=0.023$, pooled SEM $=0.0911)$. During 0 to 18 min postexercise, minute of test $(P<0.001$, pooled SEM $=0.0896)$ was significant. During 33 to 78 min postexercise, minute of test $(P=0.004)$ and interaction of treatment $\times$ pregnancy status $\times$ day of experiment $\times$ minute of test $(P=0.022)$ were significant $($ pooled SEM $=0.115)$.

remained greater for $1 \mathrm{~h}$ postexercise than preexercise values (Blake et al., 1982).

Blood $\mathrm{pCO}_{2}$ and Concentrations of $\mathrm{HCO}_{3}^{-}$. During treadmill tests, blood $\mathrm{pCO}_{2}$ and $\mathrm{HCO}_{3}{ }^{-}$concentrations responded in a similar fashion as treadmill tests progressed (Figures 6 and 7) and as previously reported (Davidson and Beede, 2003). Patterns of total $\mathrm{CO}_{2}$ concentrations were similar (results not shown). During the exercise portion of tests, blood $\mathrm{pCO}_{2}$ and concentrations of $\mathrm{HCO}_{3}{ }^{-}$declined approximately $25 \%$ as time of tests progressed and during the first $6 \mathrm{~min}$ postexercise $(P<0.001$; Figures 6 and 7$)$. During the remaining time postexercise (9 to $75 \mathrm{~min}$ after treadmill tests), $\mathrm{pCO}_{2}$ and $\mathrm{HCO}_{3}{ }^{-}$concentrations increased in all groups, returning to approximately preexercise values $(P<0.001$; Figures 6 and 7$)$. Increased respira- tion rates may have influenced changes in blood $\mathrm{pCO}_{2}$ and $\mathrm{HCO}_{3}{ }^{-}$concentrations during the exercise and postexercise portions of tests.

After $60 \mathrm{~d}$ of training and during the exercise portion of tests, cows that exercised had slightly greater blood $\mathrm{pCO}_{2}$ compared with cows that did not exercise (interaction of $\mathrm{T} \times$ day of experiment, $P=0.046$; Figure 6). Concentrations of $\mathrm{HCO}_{3}{ }^{-}$were about $5 \%$ greater for $\mathrm{E}$ cows $(25.3 \pm 0.031 \mathrm{mmol} / \mathrm{L})$ compared with $\mathrm{NE}$ cows $(24.0 \pm 0.034 \mathrm{mmol} / \mathrm{L}, P<0.007)$. From 33 to 78 min postexercise, regardless of day of experiment and minute of test, blood $\mathrm{pCO}_{2}$ tended to drop about $5 \%$ for cows in $\mathrm{P}, \mathrm{NE}(37.5 \pm 0.64 \mathrm{mmol} / \mathrm{L})$ compared with cows in $\mathrm{P}, \mathrm{E}(39.4 \pm 0.49 \mathrm{mmol} / \mathrm{L}, P=0.057)$, whereas cows in NP, NE $(41.8 \pm 0.47 \mathrm{mmol} / \mathrm{L})$ and NP, $\mathrm{E}(41.7 \pm 0.46 \mathrm{mmol} / \mathrm{L})$ had similar $\mathrm{pCO}_{2}$ concentra- 
tions. Similarly, dairy cows that exercised for 8 wk at 4 $\mathrm{km} / \mathrm{h}$ for $2 \mathrm{~h}$ maintained homeostatic control of blood $\mathrm{CO}_{2}, \mathrm{HCO}_{3}^{-}$, and base excess during exercise compared with preexercise values (Blake et al., 1982).

In the present study, pregnant cows had greater blood $\mathrm{pH}$ and lesser blood $\mathrm{pCO}_{2}$ and concentrations of $\mathrm{HCO}_{3}{ }^{-}$compared with NP cows regardless of day or minute of test $(P<0.05$; Figures 6 and 7$)$. Similar results were not found in the literature. Pregnant cows likely have larger plasma volume than nonpregnant cows, which may have resulted in differences in blood $\mathrm{pH}, \mathrm{pCO}_{2}$, and concentrations of $\mathrm{HCO}_{3}{ }^{-}$. Even though the absolute concentrations were different for cows in $\mathrm{P}$ and NP, the relative changes of acid-base status during the treadmill tests were similar.

Additionally, the feeding of a negative DCAD on d 60 of experiment may have decreased blood $\mathrm{pH}, \mathrm{pCO}_{2}$, and concentrations of $\mathrm{HCO}_{3}{ }^{-}$at min 0 of tests compared with $\mathrm{d} 0$ and 30 when a positive DCAD was fed $(P<$ 0.001; Figures 5, 6, and 7). Nonetheless, the relative changes of acid-base status during treadmill tests were similar whether cows were fed a positive (d 0 and 30 tests) or negative DCAD (d 60 test). Pregnant cows were able to maintain acid-base homeostasis during metabolic acidosis (greater plasma lactate concentrations) while exercising when fed a diet with a negative DCAD.

\section{Mineral Element Concentrations During Treadmill Tests}

During exercise, blood $\mathrm{K}^{+}$concentrations increased by approximately $25 \%$ as minute of treadmill tests progressed on all days of the experiment $(P<0.001$; Figure 8). Similarly, Hereford calves that exercised had greater serum $\mathrm{K}^{+}$concentrations (Kuhlmann et al., 1985; Fosha-Dolezal and Fedde, 1988). Increased $\mathrm{K}^{+}$concentrations may result from release of $\mathrm{K}^{+}$from muscle cells or incomplete uptake of $\mathrm{K}^{+}$during repolarization in muscle.

On d 0 of the experiment, blood $\mathrm{K}^{+}$concentrations were similar among all treatment groups as minute of test increased. After 30 and $60 \mathrm{~d}$ of exercise, NP cows that exercised had lesser $\mathrm{K}^{+}$concentrations compared with NP cows that did not exercise. This response was not observed in pregnant cows that were exercised until d 60 (interaction of $\mathrm{T} \times \mathrm{PS} \times$ day of experiment, $P$ $=0.023$; Figure 8$)$. During 0 to $18 \mathrm{~min}$ after treadmill tests (postexercise), all cows responded similarly with $\mathrm{K}^{+}$concentrations declining as time postexercise increased $(P<0.001 ;$ Figure 8$)$. Fosha-Dolezal and Fedde (1988) showed that exercise training of calves reduced the increase in serum $\mathrm{K}^{+}$concentrations during exercise compared with pretraining values. In another experiment, exercise training of nonpregnant, nonlactating dairy cows did not affect the pattern of blood concentrations of $\mathrm{K}^{+}$during treadmill tests (Davidson and Beede, 2003).

In the current study, neither pregnancy status nor exercise training altered blood $\mathrm{Cl}^{-}$nor $\mathrm{iCa}^{2+}$ concentrations during exercise or postexercise portions of treadmill tests. But, $\mathrm{P}$ cows had greater $\mathrm{Cl}^{-}$concentrations than NP cows on d 60 of the experiment when all cows were fed the negative DCAD (108 vs. $104 \pm$ $0.5, \mathrm{mmol} / \mathrm{L}$; interaction of PS $\times$ day of experiment; $P$ $<0.025)$. In other research, exercise or work activity of calves and draft oxen did not affect plasma $\mathrm{Ca}^{2+}$ or $\mathrm{Cl}^{-}$concentrations (Blum et al., 1979; Zanzinger and Becker, 1992).

The relatively small changes of $\mathrm{iCa}^{2+}$ and $\mathrm{Cl}^{-}$concentrations may reflect changes in plasma volume due to movement of water from plasma to extracellular, intracellular, or interstitial fluid compartments of muscle. Hereford calves or lambs that were exercised had approximately a 7 to $9 \%$ shift of water volume from blood to muscle compartments during exercise (Kuhlmann et al., 1985; Apple et al., 1994). Additionally, $\mathrm{Cl}^{-}$concentrations in $\mathrm{P}$ cows were greater in all 3 treadmill tests (d 0,30, and 60) compared with that of NP cows (results not shown).

\section{HCT and HGB During Treadmill Test}

During exercise and postexercise portions of treadmill tests, exercise training did not affect blood HCT and HGB concentrations. On the other hand, on d 60 during exercise portion of treadmill tests, increases of HCT and HGB concentrations were reduced by about $10 \%$ for P compared with NP cows versus values on $\mathrm{d}$ 0 and 30 of the experiment (interaction of PS $\times$ day of experiment $\times$ minute of test, $P=0.035$; Figure 9 ). Hematocrit increased during exercise at a faster rate for NP cows compared with $\mathrm{P}$ cows as parturition approached. During min 0 to 18 postexercise of treadmill tests, HCT and HGB concentrations declined as test progressed with the greatest change occurring for NP cows on d 60 compared with their values on d 0 and 30 and compared with responses of $\mathrm{P}$ cows (interactions of PS $\times$ day of experiment, $P<0.001$; interaction of PS $\times$ minute of test, $P=0.042$; Figure 9). After $33 \mathrm{~min}$ postexercise, differences in HCT and HGB concentrations were not detected.

Transient changes in HCT and HGB as treadmill tests progressed are suggestive of possible fluid shifts and changes in plasma volume. Humans exercising at submaximal and maximal intensities had hemoconcentration of circulating blood with 7.1 and 13.0\% decreases in plasma volume, respectively (Novosadova, 

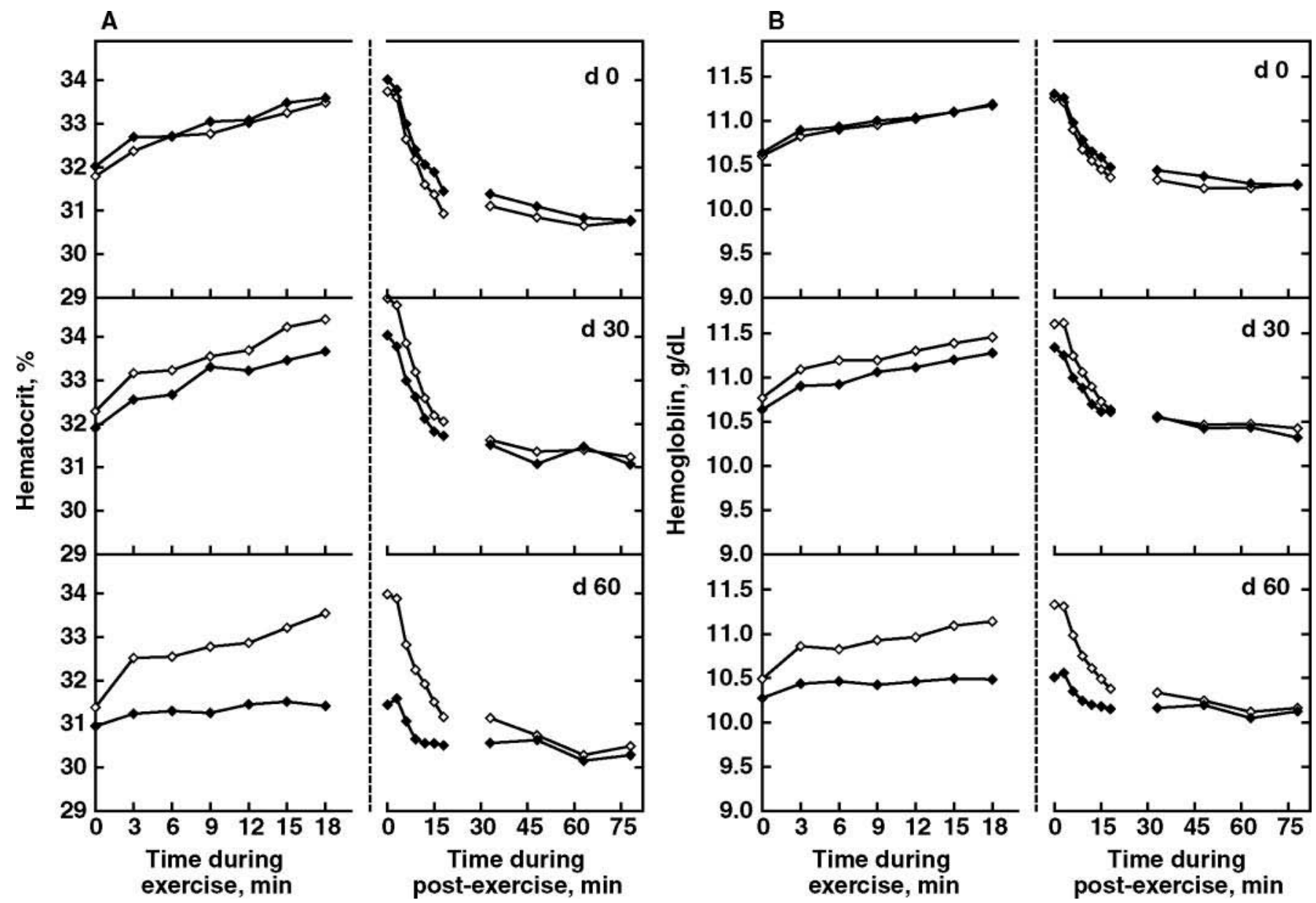

Figure 9. Blood hematocrit (HCT) and hemoglobin (HGB) concentrations during exercise and postexercise portions of treadmill tests on d 0, 30, and 60 of the experiment. Pooled across exercise treatments, symbols represent nonpregnant $(\diamond)$ and pregnant $(\diamond)$. Panel A shows results for HCT concentrations, and panel B shows results for HGB concentrations. During exercise, blood HCT and HGB concentrations were affected by minute of test $(P<0.001)$ and interaction of pregnancy status $\times$ day of experiment $\times$ minute of test $(P=0.035$, pooled SEM $=0.831$ and 0.256 , respectively). During 0 to 18 min postexercise, minute of test $(P<0.001)$, interaction of pregnancy status $\times$ day of experiment $(P<$ $0.001)$, and interaction of pregnancy status $\times$ minute of test $(P=0.042$, pooled SEM $=0.735$ and 0.249 , respectively $)$ were significant. During 33 to $78 \mathrm{~min}$ postexercise, minute of test was significant $(P<0.001$, pooled SEM $=0.656$ and 0.226 , respectively).

1977). In the current study, pregnancy status affected concentrations of HCT and HGB, possibly due to differences of plasma volume.

\section{CONCLUSIONS}

Physical fitness improved for pregnant and nonpregnant cows by exercise training. The ability to continue treadmill tests for greater lengths of time, and reductions in heart rates and plasma lactate concentrations during given workloads were indicative of improved physical fitness after $60 \mathrm{~d}$ of exercise training. Additionally, pregnancy status and day of pregnancy greatly affected heart rates during treadmill tests and at rest, and the time to end of treadmill test near parturition, at d 60 of the experiment. Reduced plasma lactate concentrations during exercise after $60 \mathrm{~d}$ of exercise training likely contributed to improved acid-base homeostasis of exercised cows compared with nonexercised cows. Cows that exercised had greater $\mathrm{pCO}_{2}$ and $\mathrm{HCO}_{3}{ }^{-}$concentrations during treadmill tests on $\mathrm{d}$ 60 compared with nonexercised cows. Exercise training did not affect blood concentrations of $\mathrm{Cl}^{-}$or $\mathrm{iCa}^{2+}$, but did alter $\mathrm{K}^{+}$concentrations during treadmill tests on d 60 of the experiment. Pregnant cows had similar responses in acid-base regulation as nonpregnant cows. Moreover, pregnant cows had lower HCT and HGB with exercise training than nonpregnant cows, possibly due to differences of blood plasma volume. We conclude that regardless of pregnancy status, exercise training of 
nonlactating dairy cows improved their physical fitness and ability to maintain acid-base homeostasis during treadmill exercise tests.

\section{ACKNOWLEDGMENTS}

The special assistance of Robert Tempelman, Rebekah Devins, Jessica Kerr, Jason Canaday, and Kasey Moyes, as well as the help of many other undergraduate students and staff at the Michigan State University Dairy Teaching and Research Center, is gratefully noted. Partial financial support of the C. E. Meadows Endowment is acknowledged. This study was part of the CSREES/USDA NC-1119 regional project.

\section{REFERENCES}

Aguera, E. I., M. D. Rubio, R. Vivo, R. Santisteban, A. Munoz, and F. Castejon. 1995. Blood parameter and heart rate response to training in Andalusian horses. Rev. Esp. Fisiol. 51:55-64.

Apple, J. K., J. E. Minton, K. M. Parsons, M. E. Dikeman, and D. E. Leith. 1994. Influence of treadmill exercise on pituitary-adrenal secretions, other blood constituents, and meat quality of sheep. J. Anim. Sci. 72:1306-1314.

Blake, J. T., J. D. Olsen, J. L. Walters, and R. C. Lamb. 1982. Attaining and measuring physical fitness in dairy cattle. J. Dairy Sci. 65:1544-1555.

Blum, J. W., W. Bianca, F. Naf, P. Kunz, J. A. Fischer, and M. Da Prada. 1979. Plasma catecholamine and parathyroid hormone responses in cattle during treadmill exercise at simulated high altitude. Horm. Metab. Res. 11:246-251.

Clapp, J. F. 1985. Maternal heart rate in pregnancy. Am. J. Obstet. Gynecol. 152:659-660.

Davidson, J. A., and D. K. Beede. 2003. A system to assess fitness of dairy cows responding to exercise training. J. Dairy Sci. 86:28392851.

Ehrlein, H. J., H. Honicke, W. V. Engelhardt, and G. Tolkmitt. 1973. Heart frequency during standardized exercise as a measure of the working capacity of horses. Zentralbl. Veterinaermed. Reihe A. 20:188-208.
Erkkola, R. 1976. The influence of physical training during pregnancy on physical work capacity and circulatory parameters. Scand. J. Clin. Lab. Invest. 36:747-754.

Fosha-Dolezal, S. R., and M. R. Fedde. 1988. Serum potassium during exercise in Hereford calves: Influence of physical conditioning. J. Appl. Physiol. 65:1360-1366.

Fregin, G. F., and D. P. Thomas. 1983. Cardiovascular response to exercise in the horse: A review. Pages 76-90 in Equine Exercise Physiology. D. H. Snow, S. G. B. Perrson, and R. J. Rose, ed. Burlington Press Ltd., Cambridge, UK.

Jones, J. H., K. E. Longworth, A. Lindholm, K. E. Conley, R. H. Karas, S. R. Kayar, and C. R. Taylor. 1989. Oxygen transport during exercise in large mammals. I. Adaptive variation in oxygen demand. J. Appl. Physiol. 67:862-870.

Kuhlmann, W. D., D. S. Hodgson, and M. R. Fedde. 1985. Respiratory, cardiovascular, and metabolic adjustments to exercise in the Hereford calf. J. Appl. Physiol. 58:1273-1280.

Lamb, D. R. 1984. The nature of exercise physiology. Pages 1-9 in Physiology of Exercise: Responses and Adaptations. 2nd ed. Macmillan Publishing Co., New York, NY.

Morton, M. J., N. S. Paul, G. R. Compos, M. V. Hark, and J. Metcalfe. 1985. Exercise dynamics in late pregnancy: Effects of physical training. Am. J. Obstet. Gynecol. 152:91-97.

Mundie, T. G., A. J. Januszkiewicz, D. B. Rayburn, D. G. Marin, and G. R. Ripple. 1991. Effects of conditioning and maximal incremental exercise on oxygen consumption in sheep. Am. J. Vet. Res. 52:1019-1023.

Novosadova, J. 1977. The changes in hematocrit, hemoglobin, plasma volume and proteins during and after different types of exercise. Eur. J. Appl. Physiol. Occup. Physiol. 36:223-230.

Piguet, M., R. M. Bruckmaier, and J. W. Blum. 1993. Treadmil exercise of calves with different iron supply, husbandry, and work load. Zentralbl. Veterinarmed. Reihe A. 40:456-465.

Rodiek, A. V., L. M. Lawrence, and M. A. Russell. 1987. Cardiovascular effects of intermittent or continuous treadmill conditioning in horses. J. Equine Vet. Sci. 7:14-19.

SAS Institute. 1999. Release 8.2. SAS Inst. Inc., Cary, NC.

Thomas, D. P., G. F. Fregin, N. H. Gerber, and N. B. Ailes. 1983. Effects of training on cardorespiratory function in the horse. Am. J. Physiol. 245:R160-R165.

Zanzinger, J., and K. Becker. 1992. Blood parameters in draught oxen during work: Relationship to physical fitness. Comp. Biochem. Physiol. 102A:715-719. 